\title{
Tecnologias Sociais Indígenas Amazônicas e Ensino de História
}

\section{Amazonian Indigenous Social Technologies and History Teaching}

\author{
Eliane Rego Vasconcelos ${ }^{1}$ \\ ${ }^{1}$ Secretária Estadual da Educação, Amazonas, Brasil. https://orcid.org/0000-0001-5844-784X E-mail: elianerego81@hotmail.com *Autor de \\ correspondência
}

\author{
Palavras-chave \\ Tecnologias sociais indígenas \\ Ensino de história \\ Cultura
}

\begin{abstract}
A dimensão cultural merece destaque, especialmente no contexto da educação científica amazônica que envolve o ensino de história, pois encontra-se mesclada a diversas práticas e crenças que fazem parte do cotidiano local. O principal objetivo desse projeto foi estudar aspectos culturais das sociedades amazônicas na educação básica, com foco nas tecnologias. Para isso, desenvolveu-se uma pesquisa-ação na escola. Os sujeitos desenvolveram pesquisa bibliográfica e de campo sobre a temática: tecnologias sociais indígenas na Amazônia. Os resultados do projeto de pesquisa foram: aproximação da cultura indígena amazônica com o cotidiano dos alunos, processos de ensino e aprendizagem inovadores como: diálogos com professores pesquisadores da UFAM, interdisciplinaridade na disciplina de história, através da problematização com outras ciências, como a geografia, ciências, física, química e outras áreas afins.
\end{abstract}

The cultural dimension deserves to be highlighted, especially in the context of Amazonian scientific education that involves the teaching of history, as it is mixed with various practices and beliefs that are part of the local daily life. The main objective of this project was to study cultural aspects of Amazonian societies in basic education, focusing on technologies. For that, an action research was developed in the school. The subjects developed bibliographic and field research on the theme: indigenous social technologies in the Amazon. The results of the research project were: bringing Amazonian indigenous culture closer to students' daily lives, innovative teaching and learning processes such as: dialogues with UFAM research professors, interdisciplinarity in the discipline of history, through problematization with other sciences, such as geography , science, physics, chemistry and other related fields.

\section{INTRODUÇÃO}

A Amazônia consiste na maior biodiversidade do planeta, considerada por muitos a última fronteira de expansão para o capitalismo. Por isso não é exagero dizer que ela está no epicentro das discussões socioambientais globais. No contexto socioambiental, a dimensão cultural merece destaque, especialmente no contexto da educação científica amazônica que encontra-se mesclada a diversas práticas e crenças que fazem parte do cotidiano local. Mediar conhecimentos de naturezas (conhecimentos tradicionais e conhecimento científico) diferentes é muito complexo. No Brasil, de um modo geral, pode-se afirmar que essa mediação pouco acontece, em vez disso, o que se vê é a tentativa de superposição do conhecimento científico/escolar sobre o conhecimento popular (BAPTISTA, 2010). Ou seja, prioriza-se os conhecimentos científicos em detrimento daqueles vindos da realidade sociocultural dos sujeitos. Nas palavras de Freire (2011, p. 26), esta atitude configura-se no [...] termo extensão, está implícita a ação de levar, de transferir, de entregar, de depositar algo em alguém, ressalta, nele, uma conotação indiscutivelmente mecanicista. [...], a qual não contempla a dialogicidade que tem sido considerada necessária para realização de uma educação científica e tecnológica que leve os sujeitos a continuar aprendendo.

Quando se opta pela não problematização das contradições, diferenças e discordâncias. A procedência do conhecimento tradicional (ainda que se considere suas diferenças) é muito próxima do que se conhece por senso comum, que ao longo do tempo foi se enraizando por meio da cultura do lugar.

O senso comum indica uma visão de mundo fragmentada e até contraditória. São conceitos, significados e valores que adquirimos espontaneamente, pela convivência, no ambientem que vivemos. O senso comum nasce do processo de acostumar-se a uma explicação ou compreensão da realidade, sem que ela seja questionada (GHEDIN, 2012).

A humanidade tem por característica a busca de conhecimento sobre o ambiente onde vive, sendo comum que grupos humanos, como comunidades ribeirinhos, quilombolas, indígenas, etc., atribuam, durante essa busca, significados e símbolos aos acontecimentos e ao mundo que conhecem; semelhante ao que ocorre quando optamos por um senso comum sobre os fenômenos do mundo (BAPTISTA, 2010). Nesse movimento de conhecer e significar, se produz a cultura, sempre mutante, a qual revela uma explicação particular da natureza e do mundo. Nesse pensar, a cultura 
pode ser considerada como um conjunto de valores, opiniões, expectativas e atos que revelam a maneira como vemos o mundo. Sob este ponto de vista, tanto conhecimentos científicos quanto tradicionais podem ser percebidos como parte de culturas que podem dialogar. (LESSA, 2004; BAPTISTA, 2010).

É importante ter consciência que a ciência possui uma linguagem própria e maneiras consagradas de realizar suas atividades e comunicar-se que se diferenciam de conhecimentos de outra natureza. Desse modo, não basta aproximar o tradicional que pertence ao contexto local do conhecimento científico, é necessário levar os professores, estudantes e acadêmicos a perceberem essas diferenças e a descobrirem a possibilidade de aprender ainda mais a partir de sua realidade local (BAPTISTA, 2010; FREIRE, 2011).

$\mathrm{Na}$ disciplina de história um dos principais temas abordados é o ser humano e seu processo evolutivo. Com destaque para características culturais como a fala, a escrita, a criação e domínio de técnicas diversas realizadas graças a capacidade de pensar e refletir sobre o ambiente em que vive. Ao observar seu habitat a humanidade começou a desenvolver ferramentas e instrumentos que consolidaramse na história como tecnologias. Essas transformaram o modo de viver e desenvolver das sociedades primitivas. A tecnologias eram fabricadas, primeiramente de ossos, madeiras e rochas. No decorrer da linha evolutiva as tecnologias tiveram papel de destaque no desenvolvimento de atividades como a agricultura e desenvolvimento de armas. Isto, seguramente, tornou cada vez mais complexas as sociedades.

$\mathrm{Na}$ Amazônia encontramos etnias indígenas que são detentoras de tecnologias estão cada vez mais inseridas no seu cotidiano. Tudo visando acelerar o processo de produção e melhorar a qualidade de vida dessa população.

Considera-se relevante o exercício da cidadania pela população local a partir do conhecimento sobre esses temas. Ao considerar o processo educativo, um elemento central para essa conjuntura, cabe questionar como a dimensão cultural, do contexto regional, tem sido inseridas e organizadas e resultado relevantes na formação de professores de ciências e Biologia na Amazônia. Tendo em vista sua problematização durante a educação básica.

Observando a diversidade cultural presente no contexto amazônico faz-se necessário a elaboração de um projeto que aproxime a comunidade escolar da cultura tradicional e tecnológica que é repassada para as gerações futuras.

O objetivo desse estudo foi verificar como os conhecimentos acerca das tecnologias criadas e utilizadas por sociedades indígenas da Amazônia estão presentes no cotidiano da escola. Para isso, analisou-se as tecnologias confeccionadas e desenvolvidas pelas comunidades indígenas da Amazônia no contexto do ensino de história.

\section{MATERIAL E MÉTODOS}

Esse projeto se desenvolveu por meio do Programa Ciência na Escola (PCE) do Governo Estadual do Amazonas. O Programa Ciência na Escola é uma ação criada pela FAPEAM direcionada à participação de professores e estudantes de escolas públicas estaduais do Amazonas e municipais de Manaus em projetos de pesquisa científica e de inovação tecnológica a serem desenvolvidos nas escolas.

Dentre os principais objetivos desse projeto está o de apoiar a participação de professores e estudantes do 50 ao 9o ano do ensino fundamental, da 1 à à 3 a série do ensino médio e suas modalidades: Educação de Jovens e Adultos, Educação Escolar Indígena, Atendimento Educacional Específico e Projeto Avançar, em projetos de pesquisa a serem desenvolvidos em escolas públicas estaduais sediadas no Amazonas e municipais de Manaus.

O Projeto é uma iniciativa do Governo Estadual que oferece benefícios financeiros e pedagógicos para as escolas participantes. Cada escola poderá ter até quatro projetos submetidos e aprovados. Para aprovação do projeto os professores da Secretária do Estado de Educação- SEDUC e Secretária Municipal de Educação-SEMED do Estado do Amazonas devem submeter uma proposta de pesquisa inédita, as propostas aprovadas recebem apoio financeiro da Fundação de Amparo a Pesquisa do Estado do AmazonasFAPEAM sendo uma bolsa de fomento para Professor Jovem Cientista- PJC e, atualmente três bolsas para Iniciação Cientifica Júnior-IC-JR destinada aos alunos participantes. As propostas submetidas são analisadas por uma equipe técnica da FAPEAM que elaborou uma lista classificatória dos projetos julgados recomendados e não recomendados, a partir dessa lista classificatória ocorre a implementação e concessão dos benefícios.

Diante disso, a pesquisa aconteceu por meio de uma pesquisa ação. A pesquisa-ação consiste em um tipo de pesquisa que envolve uma ação relacionada a resolução de um problema que alcança um coletivo (THIOLLENT, 2009).

Nesse tipo de metodologia é essencial a participação das pessoas implicadas nos problemas abordados, no caso da presente proposta, os professores de história e estudantes da educação básica. Durante a realização do projeto por meio da pesquisa-ação, a aprendizagem sobre o tema abordado acontece associada a um processo de investigação na escola, protagonizado por estudantes e professores.

Com base nisso, o projeto se realizou em quatro (4) etapas, são elas: 1) pesquisa bibliográfica, 2) pesquisa de campo, 3) Problematização de tecnologias sociais indígenas 
por meio do ensino de História na escola e 4) Socialização dos resultados da pesquisa-ação junto a comunidade escolar. Materiais utilizados foram: computador, data-show, gravador, livros, folder, papeis, tnt, impressora, cola e outros.

Etapas da pesquisa:

1) PESQUISA BIBLIOGRÁFICA: A primeira etapa consistiu na pesquisa bibliográfica sobre o tema central da proposta. Nessa etapa, os alunos do sexto e sétimo ano do ensino fundamental consultaram revistas científicas e livros para aproximarem-se do tema, tecnologias indígenas, auxiliados pelo professor proponente.

2) PESQUISA DE CAMPO: nesta etapa os estudantes fizeram entrevistas realizadas com pessoas que moram ou são descendentes de comunidades indígenas, as quais poderão ser moradores da cidade de Manaus- AM, familiares ou ainda conhecidos. O objetivo dessa etapa era conhecer tecnologias indígenas que fazem parte do cotidiano dos estudantes que destacam aspectos importantes da cultura amazônica para o ensino de história. A técnica da entrevista impõe a elaboração antecipada de questões que seguem uma sequência unificada. Dessa maneira, o momento da entrevista pode ser mais proveitoso e colaborar com o alcance dos objetivos do projeto (ROSA; ARNOLDI, 2006). Desse modo, se elaborarão questões semiestruturadas e projetivas. De acordo com Minayo (2008. p. 65), a entrevista projetiva constitui-se em uma técnica que utiliza: [...] dispositivos visuais, como filmes, vídeos, pinturas, gravuras, fotos, poesias, contos, e redações de outras pessoas [...] esse tipo de entrevista permite convidar os sujeitos a discorrer sobre o que vê ou lê de maneira mais espontânea. A intensão é favorecer a reflexão a partir de fragmentos de textos ou imagens publicados em livros e revistas sem o sentimento de erro ou acerto da questão, já que as questões eram de natureza reflexiva.

Os questionários foram disponibilizados para os estudantes realizarem as entrevistas se constituiam de questões abertas, de caráter problematizador que exigiram dos sujeitos uma leitura e reflexão cuidadosa no momento da entrevista.

3) PROBLEMATIZAÇÃO DE TECNOLOGIAS SOCIAIS POR MEIO DO ENSINO DE HISTÓRIA NA ESCOLA:

Esta etapa consistiu na discussão dos resultados da pesquisa bibliográfica e de campo junto a comunidade escolar e estudantes e professores da Universidade Federal do Amazonas - UFAM, participantes no projeto. O objetivo desse momento foi realizar grupos focais (áudio gravados) junto a professores e estudantes da escola para discutir a relevância, presença e abordagem da dimensão cultural no contexto da educação básica. Nesse momento, foram problematizados temas culturais considerados relevantes no contexto regional e que podem envolver diversos assuntos científicos presentes no currículo e indicados meios didáticos e pedagógicos que facilitem discussões dessa natureza no contexto escolar.

4) SOCIALIZAÇÃO DOS RESULTADOS DA PESQUISA-AÇÃO JUNTO A COMUNIDADE ESCOLAR: Nesse momento, estudantes e professores juntamente com todos os atores da escola participaram da organização de uma exposição dos resultados encontrados a partir do projeto, com ênfase para os objetos confeccionados por descendentes de populações indígenas presentes na cidade de Manaus.

Sendo assim, os sujeitos envolvidos na pesquisa-ação foi professores da educação básica, docentes e estudantes da UFAM, estudantes do ensino fundamental e atores da comunidade escolar (vizinhos, familiares, amigos da escola etc.). O local onde o projeto se realizou será a própria escola estadual onde a proponente atua como professora.

\section{RESULTADOS E DISCUSSÃO}

Em resposta ao objetivo proposto foi verificado a aproximação da cultura indígena amazônica com o cotidiano dos alunos. Durante a realização do projeto os alunos pesquisaram algumas etnias indígenas do Estado do Amazonas identificando traços culturais presentes na sua vivencia familiar, seja através de objetos confeccionados pelas etnias indígenas atuais ou pelas histórias presentes na memória familiar que retratam aspectos da sua história local.

Ao todo foram entrevistados 10 pessoas com ascendência indígena, os traços culturais encontrados nas entrevistas foram organizados e agrupados de acordo com sua natureza conforme a tabela 1 .

Tabela 1. Traços culturais encontrados nas entrevistas.

\begin{tabular}{|c|}
\hline CARACTERÍSTICAS CULTURAIS \\
\hline Instrumentos de cozinha \\
\hline Máscaras com simbolismo indigena \\
\hline Instrumentos de caça \\
\hline
\end{tabular}

Outro resultado alcançado foi Processos de ensino e aprendizagem inovadores como: diálogos com professores pesquisadores da Universidade Federal do Amazonas (UFAM) realizou durante a vigência do projeto várias palestras foram realizadas na escola Estadual, local da pesquisa, algumas delas foram ministradas pelos estagiários, professores pesquisadores da universidade. Dessa forma os alunos tiveram a oportunidade de conhecer um pouco mais sobre a importância do conhecimento científico no contexto amazônico. 
Assim foi possível concluir que vários conceitos estudados estavam presentes no cotidiano dos discentes, esses conceitos estavam presentes nas vivencias, emoções, linguagens, as rodas de conversas ampliaram os conceitos como o de tecnologia, cultura.

Foi possível observar que a interação tem papel fundamental no desenvolvimento da mente. A partir da interação entre diferentes sujeitos se estabelecem processos de aprendizagem e, por consequência, o aprimoramento de suas estruturas mentais existentes desde o nascimento. Nesse processo, o ser humano necessita estabelecer uma rede de contatos com outros seres humanos para incrementar e construir novos conceitos.

O outro social, se torna altamente significativo para as crianças que estão no auge do seu desenvolvimento, uma vez que assume o papel de meio de verificação das diferenças entre as suas competências e as dos demais, para, a partir desse processo, formular hipóteses e sintetizar ideias acerca desses laços construídos, tornando um processo interpessoal, num processo intrapessoal. Ao tratar das funções psicológicas superiores no desenvolvimento da criança, Melo e Teixeira (2012) citam que Vigotski as classifica em dois momentos: Primeiro no nível social, e depois, no nível individual, primeiro entre pessoas (interpsicológica), e depois, no interior da criança (intrapsicologica), isso se aplica igualmente para atenção voluntária, para a memória logica e para a formação de conceitos. Todas as funções superiores originaram-se das relações reais entre indivíduos humanos.

Entende-se, assim, que pela comunicação social o ser humano pode chegar ao desenvolvimento dos conceitos, que para ele significa o entendimento das palavras. $O$ que no ensino de história é fundamental, haja vista que diálogo com o outro possibilita a compreensão de diferentes percepções da História.

A Interdisciplinaridade na disciplina de história, através da problematização com outras ciências, como a geografia, ciências, física, química e outras áreas afins. Segundo Bittencourt (2018);

A interdisciplinaridade tem sido objeto de muita discussão entre professores e pesquisadores. Embora ninguém negue a sua importância na construção do conhecimento escolar não fragmentado que possibilite ao aluno uma compreensão do mundo em sua complexidade e com suas articulações inerentes entre a vida social e natureza física, biológica, química etc., o desafio é sua concretização.

Ademais, o dialogo, pesquisa e extensão com a Universidade federal do Amazonas com a escola. Sendo assim,
A tarefa do educador deve ser a de problematizar para os educandos o conteúdo que os mentaliza e não entregalo como algo já feito, acabados espaços históricos e culturais que invadem e outros que são invadidos ou penetrados, onde se impõe sistemas de valores por meio de um tecido de relações autoritárias, expressas em posições antagônicas, em relação invasores e invadidos nas quais os primeiros (invasores) agem e os segundos tem a ilusão de que agem, acreditam agir mas não o fazem e somente respondem passivamente á manipulação daquele que invade. Nesse sentido é imprescindível para o invasor despojar de significado a cultura invadida, freturar suas características e inclusive enche-la de subprodutos da cultura Invasora. ( Freire, 2013 apud RUBIO, 1997).

A realização do projeto em parceria com a Universidade, aproximando as pessoas do contexto cultural escolar, se afasta da ideia de extensão como sinônimo de 'estender' e, apresentação a extensão como um espaço de aprendizagem mútua dos espaços, símbolos e significados históricas da cultura indígena presente na escola e suas representações.

\section{CONSIDERAÇÕES FINAIS}

Com o termino do projeto " Tecnologias sociais indígenas amazônicas e o ensino de história" pode-se afirmar que houve um crescimento em termo de maturidade dos alunos bolsistas, pois, no decorrer do projeto, os alunos foram desafiados a trabalhar com prazos previamente determinados pela professora orientadora, fortalecendo valores como responsabilidade e pontualidade. A Escola participou do projeto a medida que os alunos iam expondo suas conclusões sobre as abordagens inseridas no conteúdo trabalhado na disciplina de história.

\section{AGRADECIMENTOS}

À FAPEAM pelo incentivo financeiro.

\section{REFERÊNCIAS}

DINIS-PEREIRA, J. E; ZEICHNER, K. M. A pesquisa na formação e no trabalho docente. 2a ed. Belo Horizonte:Autêntica, 2011, p. 176.

Formação de professores: pesquisas, 
representações e poder. $2^{a}$ ed. Belo Horizonte:

Autêntica,2006, p. 68.

Justiça Social - desafio para a

formação de professores. Belo Horizonte: Autêntica, 2008.

P. 167.

FREIRE, P. Extensão ou comunicação? 8.ed. Rio de Janeiro: Paz e Terra, 2011. P. 131.

Pedagogia do Oprimido. 57eda. Rio de Janeiro:

Paz e Terra, 2014a , p. 254.

GUEDIN, E. Professor Reflexivo: da alienação da técnica à autonomia da crítica. In: PIMENTA, S. G; GUEDIN, E.Professor reflexivo no Brasil: gênese e crítica de um conceito. 7ạed. São Paulo: Cortez, 2012, p. 260.

MENDES. Amazônia Modos de (0) usar. Belém: editora da UFPA, 2001, p. 105.

ROSA, M. V. F.P. C; ARNOLDI; M. A. G. C. A entrevista na pesquisa qualitativa: mecanismos para validação dos resultados. Belo Horizonte: Autêntica, 2006, p. 112.

GONÇALVEZ, C. W. P. Amazônia e Amazônias. 2. Ed. São Paulo: Contexto, 2008. 178 p. 178.

PINSK, B. Novos temas nas aulas de História São Paulo: Contexto, 2009, p.221.

VALDEMARIN, V. T. História dos métodos e materiais de ensino: escola nova e seus modos de uso. São Paulo: Cotez, 2010, p. 219

Bittencourt, C. M. F. Ensino de história: Fundamentos e métodos. 5a ed. São Paulo: Cortez, 2018. P 212

BRASIL. Fundação de Amparo a Pesquisa Do Estado Do Amazonas. Edital PCE001/2020. Disponível em: Mhttp://www.fapeam.am.gov.br/editais/edital-n-o0012020-pce/. Último acesso em 18 de outubro de 2020.

SILVEIRA, V. C. d. Simulação tridimensional da dispersão de poluentes em um modelo Euleriano considerando o efeito do meandro do vento. 2017. $143 \mathrm{f}$. Tese (Doutorado em Meterologia) - Universidade Federal de Santa Maria, Santa Maria, 2017.

MELLO, E. F. A interação social descrita por Vigotski e a sua possível ligação com a aprendizagem colaborativa através das tecnologias de rede. IX ANPERD SUL, 2012

RUBIO, E.M, Freire: Consciência e libertação (a pedagogia perigosa). Ver. Fac. Educ. Vol.23 n. 1-2 São Paulo 1997.

Submissão: 25/10/2020

Aprovado para publicação: 22/11/2020 